\title{
Phase I study of capecitabine combined with radioembolization using yttrium-90 resin microspheres (SIR-Spheres) in patients with advanced cancer
}

\author{
S J Cohen ${ }^{*}, 1$, A A Konski ${ }^{2}$, S Putnam ${ }^{3}$, D S Ball ${ }^{3}, \mathrm{~J}$ E Meyer ${ }^{4}, \mathrm{~J} Q \mathrm{Yu}^{3}, \mathrm{I}$ Astsaturov ${ }^{1}, \mathrm{C} \mathrm{Marlow}^{5}, \mathrm{~A} \mathrm{Dickens}^{5}$, \\ D N Cade ${ }^{6}$ and N J Meropol ${ }^{7}$ \\ ${ }^{1}$ Department of Medical Oncology, Fox Chase Cancer Center, Philadelphia, Pennsylvania, USA; ${ }^{2}$ Department of Radiation \\ Oncology, Karmanos Cancer Center, Wayne State University School of Medicine, Detroit, Michigan, USA; ${ }^{3}$ Department of \\ Radiology, Fox Chase Cancer Center, Philadelphia, Pennsylvania, USA; ${ }^{4}$ Department of Radiation Oncology, Fox Chase Cancer \\ Center, Philadelphia, Pennsylvania, USA; ${ }^{5}$ Clinical Trials Office, Fox Chase Cancer Center, Philadelphia, Pennsylvania, USA; ${ }^{6}$ Sirtex \\ Medical Ltd, Sydney, New South Wales, Australia and ${ }^{7}$ Division of Hematology and Oncology, University Hospitals Seidman \\ Cancer Center, Case Comprehensive Cancer Center, Case Western Reserve University, Cleveland, Ohio, USA
}

Background: This was a prospective single-centre, phase I study to document the maximum tolerated dose (MTD), dose-limiting toxicity (DLT), and the recommended phase II dose for future study of capecitabine in combination with radioembolization.

Methods: Patients with advanced unresectable liver-dominant cancer were enrolled in a $3+3$ design with escalating doses of capecitabine (375-1000 mg $/ \mathrm{m}^{2}$ b.i.d.) for 14 days every 21 days. Radioembolization with ${ }^{90} \mathrm{Y}$-resin microspheres was administered using a sequential lobar approach with two cycles of capecitabine.

Results: Twenty-four patients (17 colorectal) were enrolled. The MTD was not reached. Haematologic events were generally mild. Common grade 1/2 non-haematologic toxicities included transient transaminitis/alkaline phosphatase elevation (9 (37.5\%) patients), nausea $(9(37.5 \%))$, abdominal pain $(7(29.0 \%))$, fatigue $(7(29.0 \%))$, and hand-foot syndrome or rash/desquamation (7 (29.0\%)). One patient experienced a partial gastric antral perforation with a capecitabine dose of $750 \mathrm{mg} / \mathrm{m}^{2}$. The best response was partial response in four (16.7\%) patients, stable disease in 17 (70.8\%) and progression in three (12.5\%). Median time to progression and overall survival of the metastatic colorectal cancer cohort was 6.4 and 8.1 months, respectively.

Conclusions: This combined modality treatment was generally well tolerated with encouraging clinical activity. Capecitabine $1000 \mathrm{mg} / \mathrm{m}^{2}$ b.i.d. is recommended for phase II study with sequential lobar radioembolization.

The liver is the most common site of metastases from gastrointestinal (GI) malignancies (Hess et al, 2006). Liver-dominant metastatic disease occurs in $44 \%$ of patients following potentially curative resection of primary colorectal cancer (CRC; Manfredi et al, 2006a) and in $70 \%$ of those diagnosed with stage IV CRC (synchronous metastases; Manfredi et al, 2006b). Although systemic therapy options for metastatic CRC (mCRC) and other GI malignancies are increasing (Cunningham et al, 2004; Hurwitz et al, 2004; Grothey et al, 2013), median survival remains $\sim 2$ years. There has thus been considerable interest in liver-directed therapies such as radioembolization, with or without systemic chemotherapy, to improve the control of liver-dominant metastatic GI malignancies. 
Capecitabine, an oral fluoropyrimidine prodrug, is commonly used as an alternative to intravenous 5-fluorouracil (5-FU) in the treatment of GI cancers (Smith and Neoptolemos, 2006; Okines et al, 2007; Arkenau et al, 2008; Medley et al, 2011). The most common adverse events with capecitabine monotherapy include hand-foot syndrome, nausea, diarrhoea and fatigue (Mikhail et al, 2010). The efficacy of capecitabine combined with radiotherapy as a radiosensitizer has been studied extensively. A recent phase III multicentre comparison of capecitabine-based vs fluorouracilbased chemoradiotherapy for the neoadjuvant or adjuvant treatment of stage II-III locally advanced rectal cancer demonstrated similar results regardless of fluoropyrimidine (Hofheinz et al, 2012).

There is an expanding experience with yttrium-90 $\left({ }^{90} \mathrm{Y}\right)$ resin microspheres for the management of unresectable liver-predominant cancers. Many aspects of this therapy have been published, including microsphere properties (Bilbao et al, 2009), distribution of ${ }^{90} \mathrm{Y}$ between tumour and normal liver (dosimetry; Sangro et al, 2008; Lhommel et al, 2009; Ahmadzadehfar et al, 2011), tolerance of liver parenchyma to ${ }^{90} \mathrm{Y}$ (Lhommel et al, 2009; Dezarn et al, 2011), and procedure standardisation and patient selection (Coldwell et al, 2011; Lau et al, 2012). Randomised-controlled trials and larger prospective open-label studies have confirmed the efficacy and safety of radioembolization with 5-FU-based systemic chemotherapy in mCRC (with 5-FU, irinotecan and FOLFOX; van Hazel et al, 2004; Sharma et al, 2007; van Hazel et al, 2009; Hendlisz et al, 2010; Kosmider et al, 2011).

Currently, concomitant capecitabine treatment is contraindicated with radioembolization due to an anecdotal early report of toxicity with this combination. In Australia in the 1990s, a single patient treated with radioembolization and concurrent capecitabine developed liver failure and death. Although no other cases of liver toxicity and death with the combination have been reported, concurrent capecitabine has remained a contraindication to radioembolization. However, given the importance of capecitabine in the current management of patients with GI cancers and its potential role as a radiosensitizer, we conducted a formal phase I trial of capecitabine and radioembolization to document the maximum tolerated dose (MTD) and dose-limiting toxicities (DLTs) of the combination and to define the recommended phase II dose for further study.

\section{MATERIALS AND METHODS}

Patient eligibility. Adult patients with histologically or cytologically confirmed incurable solid tumours that were predominantly or exclusively involving the liver were included in the trial. Patients who had received any number of prior regimens were permitted provided they had an Eastern Cooperative Oncology Group performance status of $0-1$ and a life expectancy of at least 12 weeks. Eligible patients had adequate liver (total bilirubin $\leqslant$ upper limit of normal (ULN), aspartate transaminase and alanine transaminase $\leqslant 1.5 \mathrm{ULN}$ and without clinical evidence of ascites or decompensated cirrhosis), marrow (leukocytes $\geqslant 3000 / \mu \mathrm{l}$, absolute neutrophil count $\geqslant 1000 / \mu \mathrm{l}$ and platelets $\geqslant 75000 / \mu \mathrm{l})$, and kidney function (creatinine $\leqslant \mathrm{ULN}$ or estimated glomerular filtration rate $\geqslant 60 \mathrm{ml} \mathrm{min}^{-1}$ ). Upon pretreatment work-up (Coldwell et al, 2011), patients were required to have a patent portal vein and liver-to-lung shunting $<20 \%$ as measured by technetium-99m-macroaggregated albumin ( $\left.{ }^{99 \mathrm{~m}} \mathrm{Tc}-\mathrm{MAA}\right)$ on single photon emission computed tomography (CT).

Patients were excluded if they had a history of allergic reactions or hyperbilirubinemia $\geqslant 2 \mathrm{mg} / \mathrm{dl}$ attributed to prior capecitabine, had not recovered from adverse events due to agents administered $>4$ weeks earlier (excluding chronic neuropathy or alopecia), or had received any chemotherapy, radiotherapy or investigational agent $\leqslant 4$ weeks ( 6 weeks for nitrosoureas or mitomycin C) prior to screening. Pregnant/nursing women, those using insufficient birth control methods (where appropriate), or any patient who had an uncontrolled or intercurrent illness that would limit compliance with study requirements or effect the interpretation of the results were excluded.

The study was approved by the Fox Chase Cancer Center Institutional Review Board. Patients enrolled were fully informed of the nature of the trial and provided written informed consent. The trial was registered at clinicaltrials.gov (Identifier NCT00604409).

Study design and treatment. This was a prospective single-centre, phase I safety study. Patients were enrolled in a $3+3$ design with escalating doses of capecitabine $(375,600,750,900$ and $1000 \mathrm{mg} / \mathrm{m}^{2}$ b.i.d.) given for 14 days every 21 days. As $1000 \mathrm{mg} / \mathrm{m}^{2}$ b.i.d. is the highest dose typically administered to the US patients with mCRC, we chose this as our maximum dose to evaluate. Capecitabine doses were rounded to the nearest $500 \mathrm{mg}$ tablet strength. Radioembolization with ${ }^{90} \mathrm{Y}$-resin microspheres (SIR-Spheres, Sirtex Medical Limited, Sydney, Australia) was administered using a sequential lobar approach. Radioembolization was initially performed on the dominant-diseased liver lobe on day 2 of the first cycle of capecitabine. Patients were restaged after two cycles of capecitabine. Patients with bilobar disease without progression in the treated liver lobe or DLT and who met all initial eligibility criteria could receive two additional cycles of capecitabine with radioembolization to the untreated contralateral lobe on day 2 of cycle 3 of capecitabine (between days 58 and 72 from initiation of protocol therapy). These patients were reimaged after four cycles. Further treatment was at the treating physician's discretion.

For each dose level of capecitabine, in the event that no treatment-related DLT occurred in the first three patients (or only one event occurred in the first six patients) within the first 8 weeks of therapy, subsequent patients were recruited to the next dose level. If two or more out of a maximum of six patients experienced DLT at any dose, then the MTD was deemed to be exceeded and patients were enrolled to the dose level below for up to six patients at the MTD.

DLT was defined as any of the following occurring within 8 weeks of initiating protocol therapy: $\geqslant$ grade 3 non-haematologic toxicity (excluding nausea, vomiting, or diarrhoea responding to symptomatic management), grade 3 thrombocytopenia for $>5$ days, grade 4 thrombocytopenia, grade 4 granulocytopenia for $>5$ days (or associated with fever or infection), or any interruption of therapy for $>14$ days due to toxicity.

${ }^{90}$ Y-resin microspheres activity was calculated as follows:

Step 1: Calculation of percentage of tumour involvement in each treated lobe:

$$
\% \text { Tumour involvement in treated lobe }=\frac{\mathrm{V}_{\text {Tumour }}}{\mathrm{V}_{\text {Liver lobe }}} \times 100
$$

Step 2: The patient's body surface area was determined, and the implanted activity for each treated lobe was calculated:

$$
\begin{aligned}
\text { Activity }(\mathrm{GBq})= & (\mathrm{BSA}-0.2+\% \text { tumour involvement in treated lobe } / 100) \\
& \times\left(\mathrm{V}_{\text {Liver lobe }} / \mathrm{V}_{\text {Whole Liver }}\right)
\end{aligned}
$$

$\mathrm{V}_{\text {Tumour: }}$ volume of tumour in the treated lobe

$\mathrm{V}_{\text {Liver lobe: }}$ total volume of the treated lobe

$\mathrm{V}_{\text {Whole liver: }}$ total volume of the liver

For patients with bilobar disease, the restaging CT scan after two cycles of therapy was used to estimate tumour involvement of the contralateral lobe.

Step 3: Activity modification based on hepatopulmonary shunt fraction. 
As significant arteriovenous shunting in the liver is observed in $\sim 3 \%$ of patients, the hepatopulmonary shunt fraction was calculated from the percentage of ${ }^{99 \mathrm{~m}} \mathrm{Tc}$-MAA which lodged in the lungs during the pretreatment work-up. Activity was modified as follows: $10 \%$ to $<15 \%$ lung shunting $=20 \%$ reduction in calculated activity of ${ }^{90} \mathrm{Y} ; 15 \%$ to $<20 \%=40 \%$ reduction; $\geqslant 20 \%=$ patient ineligible for radioembolization.

Endpoints. The primary study objectives were the evaluation of safety, toxicity, and the recommended dose of capecitabine for further study. Secondary objectives were to obtain preliminary evidence of clinical efficacy: best overall response rate (ORR), time to progression (TTP) and overall survival (OS).

Assessments and data analyses. History and physical examination, complete blood count, serum chemistries and liver function tests were conducted within 14 days of study entry and weekly intervals thereafter. Baseline imaging (CT or magnetic resonance imaging), hepatic angiogram, and ${ }^{99 \mathrm{~m}} \mathrm{Tc}-\mathrm{MAA}$ scan (injected into the hepatic artery that was the planned treatment vessel) were performed within 28 days of study entry. Tumour response was assessed at week 6 post radioembolization, at week 14 if the contralateral lobe was treated, and at treating physician discretion thereafter. An hepatic angiogram was repeated for patients undergoing contralateral lobe treatment. Documented complete or partial responses were confirmed at least 4 weeks later and stable disease at least 6 weeks later. The minimum requirement for follow-up was at least 30 days after the end of protocol treatment (for safety) or until progression.

The overall response rate in the treated lobe was evaluated according to Response Evaluation Criteria in Solid Tumours (RECIST v. 1.0; Therasse et $a l, 2000$ ) and best ORR from the commencement of protocol treatment until disease progression/ recurrence was reported. The time to progression and OS were calculated from the date of the initiation of protocol capecitabine therapy. All adverse events (and their causal relationship to the study treatment) that occurred during the patient's study participation were recorded on standardised data capture records and their severity was rated according to NCI Common Terminology Criteria for Adverse Events (CTCAE v.3.0). All serious adverse events were monitored until resolution or until the patient stabilised. Regular monitoring and review of the toxicity reports were undertaken by the Fox Chase Cancer Center Phase I-II Committee. Descriptive statistics were applied to the toxicity assessments and the reporting of DLT and the MTD.

\section{RESULTS}

Patient characteristics. The tumour and treatment characteristics of the 24 patients enrolled are summarised in Table 1. Most patients had mCRC at diagnosis. The median time from diagnosis to the start of study treatment was 26 months. Nearly all CRC patients had received at least two chemotherapy agents and prior chemoembolization was performed in four patients (three nonCRC and one CRC). Extrahepatic disease at baseline was identified in 10 patients (including 8 of $17(47 \%)$ patients with CRC) at the following sites: lymph (2), lung (6), abdominal wall (1), lymph, lung, abdominal wall and adnexal mass (1).

Patients received a median of two cycles of capecitabine. All patients received radioembolization to the dominant-diseased lobe, which was the right lobe in 19 of 24 (79.2\%) cases. A median of 2.7 months later, the contralateral lobe was treated in $10(41.7 \%)$ patients. Median implanted activity of ${ }^{90} \mathrm{Y}$-resin microspheres was $0.98 \mathrm{GBq}$ (range $0.23-1.60) ; 1.12 \mathrm{GBq}(0.41-1.60)$ in the dominantdiseased lobe and $0.54 \mathrm{GBq}(0.23-0.81)$ in the contralateral lobe. One patient required a reduction in implanted activity due to $15 \%$

\begin{tabular}{|c|c|}
\hline Parameter & $n=24$ \\
\hline \multicolumn{2}{|l|}{ Gender, $n(\%)$} \\
\hline Male : Female & $14(58.3 \%): 10(41.7 \%)$ \\
\hline Age, median (range), years & $60(49-83)$ \\
\hline \multicolumn{2}{|l|}{ ECOG performance status, $n(\%)$} \\
\hline $0: 1$ & $13(54.2 \%): 11(45.8 \%)$ \\
\hline \multicolumn{2}{|l|}{ Ethnicity, $n$ (\%) } \\
\hline $\begin{array}{l}\text { White } \\
\text { Black }\end{array}$ & $\begin{array}{c}22 \text { (91.7\%) } \\
2 \text { (8.3\%) }\end{array}$ \\
\hline \multicolumn{2}{|l|}{ Diagnosis, $n(\%)$} \\
\hline $\begin{array}{l}\text { Colorectal adenocarcinoma } \\
\text { Carcinoid } \\
\text { Cholangiocarcinoma } \\
\text { Pancreatic neuroendocrine } \\
\text { Hepatocellular carcinoma }\end{array}$ & $\begin{array}{c}17(70.8 \%) \\
3(12.5 \%) \\
2(8.3 \%) \\
1(4.2 \%) \\
1(4.2 \%)\end{array}$ \\
\hline \multicolumn{2}{|l|}{ Stage at diagnosis, n (\%) } \\
\hline $\begin{array}{l}\text { III : IV } \\
\text { Unknown }\end{array}$ & $\begin{array}{c}2(8.3 \%): 20(83.3 \%) \\
2\end{array}$ \\
\hline Time since diagnosis, median (range), months & $26(2.5-105.2)$ \\
\hline \multicolumn{2}{|c|}{ Prior systemic therapy received (colorectal cancer patients) } \\
\hline $\begin{array}{l}\text { 5-FU } \\
\text { Oxaliplatin } \\
\text { Irinotecan } \\
\text { Bevacizumab } \\
\text { Anti-EGFR antibody }\end{array}$ & $\begin{array}{l}16(94.1 \%) \\
16(94.1 \%) \\
11(64.7 \%) \\
14(82.4 \%) \\
7(41.2 \%)\end{array}$ \\
\hline \multicolumn{2}{|c|}{ Prior therapy (non-colorectal cancer patients) } \\
\hline $\begin{array}{l}\text { Systemic therapy } \\
\text { Sandostatin } \\
\text { Chemoembolization }\end{array}$ & $\begin{array}{l}4(57.1 \%) \\
3(42.9 \%) \\
3(42.9 \%)\end{array}$ \\
\hline
\end{tabular}

lung shunting. In another, the prescribed dose of microspheres was only partially delivered due to flow stasis.

Dosing cohorts. Of the first three patients enrolled in cohort 1 (capecitabine $375 \mathrm{mg} / \mathrm{m}^{2}, n=8$ ), one patient with cholangiocarcinoma developed grade 3 hyperbilirubinemia, which was possibly related to treatment and considered a DLT. Of the next three patients enrolled, one patient with liver-predominant CRC developed grade 4 hyperbilirubinemia that was related to a malignant biliary stricture and resolved with biliary stenting. To be conservative in the assessment of toxicity as a consequence of two episodes of hyperbilirubinemia, two additional patients were enrolled into this first cohort without any DLT. Thus, enrolment continued to dose level 2.

Four patients were enrolled into the dose level 2 cohort (capecitabine $600 \mathrm{mg} / \mathrm{m}^{2}$ ), as one patient was erroneously taking half of the prescribed dose of capecitabine $\left(300 \mathrm{mg} / \mathrm{m}^{2}\right)$ and was replaced for DLT evaluation. No DLTs were observed. Of the first three patients enrolled in cohort 3 (capecitabine $750 \mathrm{mg} / \mathrm{m}^{2}$ ), one patient with $\mathrm{mCRC}$ and a large left lobe liver lesion developed a partial gastric antral perforation (grade 3) 4.4 months after ${ }^{90} \mathrm{Y}$-resin microspheres administration. This was considered 
treatment-related. Upper endoscopy did not reveal any microspheres in the stomach. A multidisciplinary case review concluded that a local field effect of radiation to the stomach from a nearly contiguous large left lobe of liver metastasis, rather than off-target administration, was the most likely cause. The cohort was expanded to six patients, with no further DLTs.

Three patients were enrolled in cohort $4\left(900 \mathrm{mg} / \mathrm{m}^{2}\right)$ and three patients were enrolled in cohort $5\left(1000 \mathrm{mg} / \mathrm{m}^{2}\right)$ with no DLTs observed. Thus, capecitabine $1000 \mathrm{mg} / \mathrm{m}^{2}$ b.i.d. was considered the recommended dose for phase II studies with concurrent lobar radioembolization.

Toxicity. Table 2 provides a summary of all adverse events by dosing level and treatment cycle. As anticipated, haematologic toxicities were relatively mild. No grade $\geqslant 3$ neutropenia or thrombocytopenia or neutropenic fever was observed. Six (33.3\%) patients had grade 3 lymphopenia, which was not clinically significant.

Common grade 1/2 non-haematologic toxicities included transaminitis/alkaline phosphatase elevation (9 (37.5\%) patients), nausea (9 (37.5\%)), abdominal pain (7 (29.0\%)), fatigue (7 $(29.0 \%))$, and hand-foot syndrome or rash/desquamation (7 $(29.0 \%)$ ); the latter being more common at higher doses of capecitabine $\left(\geqslant 750 \mathrm{mg} / \mathrm{m}^{2}\right)$. Grade $1 / 2$ changes in creatinine, bilirubin and albumin only occurred with higher doses of capecitabine $\left(\geqslant 750 \mathrm{mg} / \mathrm{m}^{2}\right)$ and with the first radioembolization procedure, while transaminitis and alkaline phosphatase elevations were reported across all doses and cycles of treatment. One patient experienced grade 3 nausea and one patient reported grade 3 diarrhoea in the first two cycles, which responded to symptomatic management and were not considered DLTs. Beyond the partial antral perforation discussed above, no serious treatment-related adverse events or deaths were recorded during an extended post-treatment median follow-up of $\sim 6$ months.

Clinical outcomes. The best response for the entire patient population in the treated liver lobe(s) was partial response in four (16.7\%) patients (three confirmed (cPR) and one unconfirmed (uPR) according to RECIST 1.0), stable disease in 17 patients (70.8\%), and progression in $3(12.5 \%)$. The median TTP and OS in the cohort of patients with largely chemotherapy-refractory CRC was 6.4 (range 1.5-29.9) months and 8.1 (mean 15.3; range 3.9-43.3) months, respectively.

\section{DISCUSSION}

This phase I trial represents the first formal clinical assessment of escalating doses of capecitabine chemotherapy combined with radioembolization in advanced liver-predominant cancer. Our data demonstrate that combined modality treatment is generally well tolerated and a dose of capecitabine $1000 \mathrm{mg} / \mathrm{m}^{2}$ b.i.d. with ${ }^{90} \mathrm{Y}$-resin microspheres lobar treatment is recommended for phase II study.

The toxicity profile noted in our study was similar to the published experience with capecitabine monotherapy (Blum, 2001; Capecitabine package insert, 2014) and ${ }^{90} \mathrm{Y}$-resin microspheres (van Hazel et al, 2004; Sharma et al, 2007; van Hazel et al, 2009; Hendlisz et al, 2010; Kosmider et al, 2011). Particular attention was given to changes in liver function and GI toxicity over the 2 months after each radioembolization procedure, given the known potential side effects of both treatment modalities (Blum, 2001; Dezarn et al, 2011; Capecitabine package insert, 2014). In a combined evaluation of 875 patients with either metastatic breast or CRC who received at least one dose of capecitabine $1250 \mathrm{mg} / \mathrm{m}^{2}$ b.i.d. as monotherapy, grade $3 / 4$ hyperbilirubinemia occurred in $22.8 \%$ of 566 patients with hepatic metastases compared with $12.3 \%$ of 309 patients without hepatic metastases at baseline (Blum, 2001; Capecitabine package insert, 2014).
Of 167 patients with grade 3/4 hyperbilirubinemia in the same analysis, $18.6 \%$ also had postbaseline elevations (grades 1 to 4 ) in alkaline phosphatase and/or elevated transaminases (27.5\%; Blum, 2001). A large meta-analysis of data with capecitabine monotherapy recorded levels of grade 3 transaminitis in $0.6-0.8 \%$ of patients and grade 3 elevations in alkaline phosphatase in $3.5 \%$ of patients (Blum, 2001).

For radioembolization, detailed retrospective analyses (Kennedy et al, 2009; Dezarn et al, 2011; Gil-Alzugaray et al, 2013) and the findings from smaller prospective trials indicate that radioembolization combined with chemotherapy is generally well tolerated (especially in the first-line setting; van Hazel et al, 2004; Sharma et al, 2007; van Hazel et al, 2009; Hendlisz et al, 2010; Kosmider et al, 2011), provided that the well-defined criteria for patient selection are met (Coldwell et al, 2011). In our study, it is important to recognise that the eligibility criteria required patients to possess a normal bilirubin as defined by the reference laboratory, and transaminases within 1.5 times the ULN. Noting that the typical criteria for patient selection for radioembolization allow patients with a bilirubin up to $2 \mathrm{mg} / \mathrm{dl}$ to be considered for treatment, our data do not address the safety in patients possessing baseline bilirubin levels above the normal range to $2 \mathrm{mg} / \mathrm{dl}$. Although we did not experience any evidence of radioembolization-induced liver disease (REILD_defined as jaundice and ascites appearing 4-8 weeks after procedure (Dezarn et al, 2011)), retrospective analyses of several large cohorts (Sangro et al, 2008; Kennedy et al, 2009; Gil-Alzugaray et al, 2013) indicate a small but significantly increased risk of REILD in the setting of heavily pre-treated disease. Sangro et al (2008) reported a $20 \%$ incidence of REILD in a cohort of patients at a single institution, but no examples in patients in whom a single lobe was treated. In a follow-up report, this group noted a decrease in REILD and severe REILD over time to 5.4 and $2.2 \%$, respectively. Thus, while we view the combination of capecitabine and radioembolization as safe in this conservatively defined patient population, caution may be warranted in the utilisation of this combined modality approach in patients with mildly compromised liver function.

A second consideration in interpreting our safety data is that patients with bilobar disease received sequential lobar therapy rather than whole-liver therapy. One of the potential advantages of the sequential lobar approach is that the tolerance of the liver parenchyma can be evaluated before treating the contralateral lobe. The safety of combining capecitabine with whole-liver radioembolization is not addressed by our study.

In our cohort of patients with refractory mCRC $(n=17)$, the response rate was $11.8 \%$ with median TTP and OS of 6.4 and 8.1 months, respectively. Although not designed as an efficacy study, our results with capecitabine-radioembolization combination therapy in a largely chemotherapy-refractory patient population are in line with recent prospective single agent radioembolization experiences in this setting. Benson et al (2013) recently reported one of the largest, treating $61 \mathrm{mCRC}$ patients with liver metastases with radioembolization alone as part of a larger prospective multicentre phase II study. PFS and OS in the mCRC patient cohort were 2.9 and 8.8 months, respectively. Seidensticker et al (2012) reported a median survival of 8.3 months in 29 mCRC patients. Finally, Cosimelli et al (2010) treated $50 \mathrm{mCRC}$ with a response rate of $24 \%$, PFS of 3.8 months, and median survival of 12.6 months. Ultimately, evaluation of the role of capecitabine with respect to efficacy requires a randomised study design in refractory mCRC patients.

There are several limitations of our trial that should be considered. As a phase I study, it enrolled patients with different types of malignancies. Thus, definitive conclusions regarding clinical efficacy must await further investigation. However, this patient population more closely represents the typical cohort 


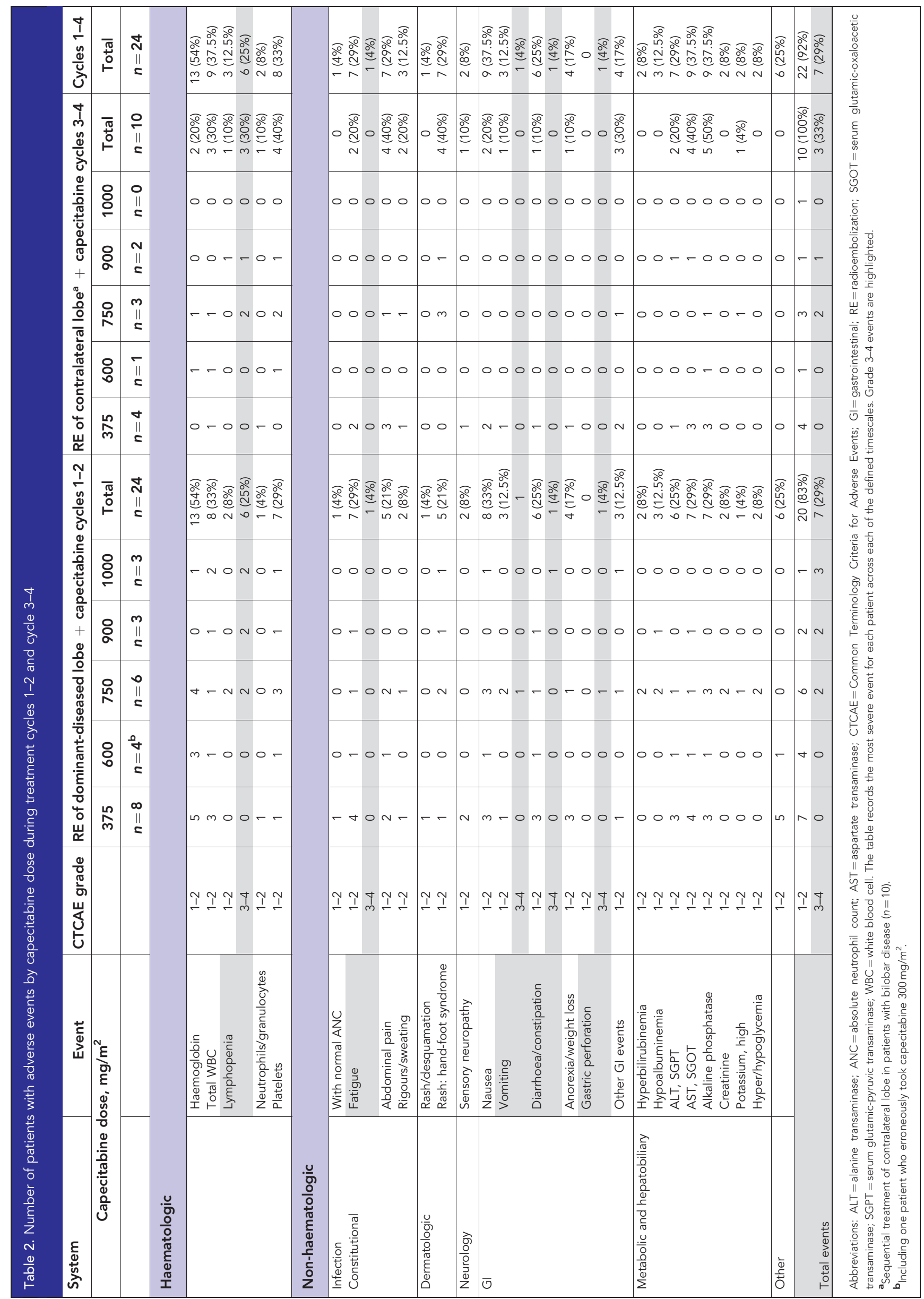


referred for radioembolization and as such we feel that the toxicity results as the primary endpoint of the study are robust. Certainly, it is important to recognise that only good performance status patients with excellent liver function tests were entered. Thus, extrapolation of safety to less robust patient populations is not possible. Our study also did not mandate long-term follow-up beyond 30 days after capecitabine. However, with extended followup over a median of $\sim 6$ months from the start of protocol treatment, we believe that the vast majority of toxicities were captured. Finally, as previously discussed, the relative contribution of capecitabine to the efficacy of ${ }^{90} \mathrm{Y}$-resin microspheres cannot be isolated in our study. However, previous studies indicate a synergy between ${ }^{90} \mathrm{Y}$-resin microspheres and systemic chemotherapy in mCRC, prolonging PFS and OS as well as increasing ORR compared with chemotherapy alone (van Hazel et al, 2004; Sharma et al, 2007; van Hazel et al, 2009; Hendlisz et al, 2010; Kosmider et al, 2011). Given the benefits of concurrent chemoradiotherapy in GI malignancies (rectal, pancreatic and oesophageal; Hofheinz et al, 2012; Diener et al, 2013; Zheng et al, 2013) further studies evaluating the relative additional benefits of concurrent chemotherapy with radioembolization are warranted.

In conclusion, our study demonstrates that the combination of capecitabine and sequential lobar radioembolization in good performance status patients with excellent liver function is well tolerated with the spectrum of toxicities approximating those seen with either modality as a single agent. Initial efficacy results appear promising and an expansion cohort study of capecitabine at $1000 \mathrm{mg} / \mathrm{m}^{2}$ b.i.d. combined with ${ }^{90} \mathrm{Y}$-resin microspheres in mCRC patients is ongoing.

\section{ACKNOWLEDGEMENTS}

Funding for research was received from Sirtex Medical Ltd.

\section{CONFLICT OF INTEREST}

David N Cade is a full time employee of Sirtex Medical Ltd, Sydney, Australia as listed in the Author Disclosure Form.

\section{REFERENCES}

Ahmadzadehfar H, Sabet A, Muckle M, Wilhelm K, Reichmann K, Biersack HJ, Ezziddin S (2011) ${ }^{99} \mathrm{~m} \mathrm{Tc}-\mathrm{MAA} /{ }^{90} \mathrm{Y}$-Bremsstrahlung SPECT/CT after simultaneous Tc-MAA $/{ }^{90} \mathrm{Y}$-microsphere injection for immediate treatment monitoring and further therapy planning for radioembolization. Eur J Nucl Med Mol Imaging 38: 1281-1288.

Arkenau HT, Arnold D, Cassidy J, Diaz-Rubio E, Douillard JY, Hochster H, Martoni A, Grothey A, Hinke A, Schmiegel W, Schmoll HJ, Porschen R (2008) Efficacy of oxaliplatin plus capecitabine or infusional fluorouracil/ leucovorin in patients with metastatic colorectal cancer: a pooled analysis of randomized trials. J Clin Oncol 26: 5910-5917.

Benson 3rd AB, Geschwind JF, Mulcahy MF, Rilling W, Siskin G, Wiseman G, Cunningham J, Houghton B, Ross M, Memon K, Andrews J, Fleming CJ, Herman J, Nimeiri H, Lewandowski RJ, Salem R (2013)

Radioembolisation for liver metastases: results from a prospective 151 patient multi-institutional phase II study. Eur J Cancer 49: 3122-3130.

Bilbao JI, de Martino A, de Luis E, Díaz-Dorronsoro L, Alonso-Burgos A, Martínez de la Cuesta A, Sangro B, García de Jalón JA (2009) Biocompatibility, inflammatory response, and recannalization characteristics of nonradioactive resin microspheres: histological findings. Cardiovasc Intervent Radiol 32: 727-736.

Blum JL (2001) The role of capecitabine, an oral, enzymatically activated fluoropyrimidine, in the treatment of metastatic breast cancer. Oncologist 6: $56-64$.
Capecitabine package insert (2014) http://www.accessdata.fda.gov/ drugsatfda_docs/label/2000/20896lbl.pdf (accessed May 14, 2014).

Coldwell D, Sangro B, Wasan H, Salem R, Kennedy A (2011) General selection criteria of patients for radioembolization of liver tumors: an international working group report. Am J Clin Oncol 34: 337-341.

Cosimelli M, Golfieri R, Cagol PP, Carpanese L, Sciuto R, Maini CL, Mancini R, Sperduti I, Pizzi G, Diodoro MG, Perrone M, Giampalma E, Angelelli B, Fiore F, Lastoria S, Bacchetti S, Gasperini D, Geatti O, Izzo F. Italian Society of Locoregional Therapies in Oncology (SITILO) (2010) Multicentre phase II clinical trial of yttrium-90 resin microspheres alone in unresectable, chemotherapy refractory colorectal liver metastases. $\mathrm{Br} J$ Cancer 103: 324-331.

Cunningham D, Humblet Y, Siena S, Khayat D, Bleiberg H, Santoro A, Bets D, Mueser M, Harstrick A, Verslype C, Chau I, Van Cutsem E (2004) Cetuximab monotherapy and cetuximab plus irinotecan in irinotecan-refractory metastatic colorectal cancer. N Engl J Med 351: 337-345.

Dezarn WA, Cessna JT, DeWerd LA, Feng W, Gates VL, Halama J, Kennedy AS, Nag S, Sarfaraz M, Sehgal V, Selwyn R, Stabin MG, Thomadsen BR, Williams LE, Salem R. American Association of Physicists in Medicine (2011) Recommendations of the American Association of Physicists in Medicine on dosimetry, imaging, and quality assurance procedures for ${ }^{90} \mathrm{Y}$ microsphere brachytherapy in the treatment of hepatic malignancies. Med Phys 38: 4824-4845.

Diener MK, Combs SE, Büchler MW (2013) Chemoradiotherapy for locally advanced pancreatic cancer. Lancet Oncol 14: 269-270.

Gil-Alzugaray B, Chopitea A, Iñarrairaegui M, Bilbao JI, Rodriguez-Fraile M, Rodriguez J, Benito A, Dominguez I, D’Avola D, Herrero JI, Quiroga J, Prieto J, Sangro B (2013) Prognostic factors and prevention of radioembolization-induced liver disease. Hepatology 57: 1078-1087.

Grothey A, Van Cutsem E, Sobrero A, Siena S, Falcone A, Ychou M, Humblet Y, Bouché O, Mineur L, Barone C, Adenis A, Tabernero J, Yoshino T, Lenz HJ, Goldberg RM, Sargent DJ, Cihon F, Cupit L, Wagner A, Laurent D. CORRECT Study Group (2013) Regorafenib monotherapy for previously treated metastatic colorectal cancer (CORRECT): an international, multicentre, randomised, placebo-controlled, phase 3 trial. Lancet 381: 303-312.

Hendlisz A, Van den Eynde M, Peeters M, Maleux G, Lambert B, Vannoote J, De Keukeleire K, Verslype C, Defreyne L, Van Cutsem E, Delatte P, Delaunoit T, Personeni N, Paesmans M, Van Laethem JL, Flamen P (2010) Phase III trial comparing protracted intravenous fluorouracil infusion alone or with yttrium-90 resin microspheres radioembolization for liver-limited metastatic colorectal cancer refractory to standard chemotherapy. J Clin Oncol 28: 3687-3694.

Hess KR, Varadhachary GR, Taylor SH, Wei W, Raber MN, Lenzi R, Abbruzzese JL (2006) Metastatic patterns in adenocarcinoma. Cancer 106: 1624-1633.

Hofheinz RD, Wenz F, Post S, Matzdorff A, Laechelt S, Hartmann JT, Müller L, Link H, Moehler M, Kettner E, Fritz E, Hieber U, Lindemann HW, Grunewald M, Kremers S, Constantin C, Hipp M, Hartung G, Gencer D, Kienle P, Burkholder I, Hochhaus A (2012) Chemoradiotherapy with capecitabine versus fluorouracil for locally advanced rectal cancer: a randomised, multicentre, non-inferiority, phase 3 trial. Lancet Oncol 13: 579-588.

Hurwitz H, Fehrenbacher L, Novotny W, Cartwright T, Hainsworth J, Heim W, Berlin J, Baron A, Griffing S, Holmgren E, Ferrara N, Fyfe G, Rogers B, Ross R, Kabbinavar F (2004) Bevacizumab plus irinotecan, fluorouracil, and leucovorin for metastatic colorectal cancer. N Engl J Med 350: $2335-2342$

Kennedy AS, McNeillie P, Dezarn WA, Nutting C, Sangro B, Wertman D, Garafalo M, Liu D, Coldwell D, Savin M, Jakobs T, Rose S, Warner R, Carter D, Sapareto S, Nag S, Gulec S, Calkins A, Gates VL, Salem R (2009) Treatment parameters and outcome in 680 treatments of internal radiation with resin ${ }^{90} \mathrm{Y}$-microspheres for unresectable hepatic tumors. Int J Radiat Oncol Biol Phys 74: 1494-1500.

Kosmider S, Tan TH, Yip D, Dowling R, Lichtenstein M, Gibbs P. Radioembolization in combination with systemic chemotherapy as first-line therapy for liver metastases from colorectal cancer (2011) J Vasc Interv Radiol 22: 780-786.

Lau WY, Kennedy AS, Kim YH, Lai HK, Lee RC, Leung TW, Liu CS, Salem R, Sangro B, Shuter B, Wang SC (2012) Patient selection and activity planning guide for selective internal radiotherapy with yttrium-90 resin microspheres. Int J Radiat Oncol Biol Phys 82: 401-407. 
Lhommel R, Goffette P, Van den Eynde M, Jamar F, Pauwels S, Bilbao JI, Walrand S (2009) Yttrium-90 TOF PET scan demonstrates high-resolution biodistribution after liver SIRT. Eur J Nucl Med Mol Imaging 36: 1696.

Manfredi S, Lepage C, Hatem C, Coatmeur O, Faivre J, Bouvier AM (2006a) Epidemiology and management of liver metastases from colorectal cancer. Ann Surg 244: 254-259.

Manfredi S, Bouvier AM, Lepage C, Hatem C, Dancourt V, Faivre J (2006b) Incidence and patterns of recurrence after resection for cure of colonic cancer in a well-defined population. Br J Surg 93: 1115-1122.

Medley L, Morel AN, Farrugia D, Reed N, Hayward N, Davies JM, Kirichek O, Thakker RV, Talbot DC (2011) Phase II study of single agent capecitabine in the treatment of metastatic non-pancreatic neuroendocrine tumours. Br J Cancer 104: 1067-1070.

Mikhail SE, Sun JF, Marshall JL (2010) Safety of capecitabine: a review. Expert Opin Drug Saf 9: 831-841.

Okines A, Chau I, Cunningham D (2007) Capecitabine in advanced gastric cancer. Expert Opin Pharmacother 8: 2851-2861.

Sangro B, Gil-Alzugaray B, Rodriguez J, Sola I, Martinez-Cuesta A, Viudez A, Chopitea A, Iñarrairaegui M, Arbizu J, Bilbao JI (2008) Liver disease induced by radioembolization of liver tumors. Cancer (2008) 112: 1538-4156.

Seidensticker R, Denecke T, Kraus P, Seidensticker M, Mohnike K, Fahlke J, Kettner E, Hildebrandt B, Dudeck O, Pech M, Amthauer H, Ricke J (2012) Matched-pair comparison of radioembolization plus best supportive care versus best supportive care alone for chemotherapy refractory liver-dominant colorectal metastases. Cardiovasc Intervent Radiol 35: 1066-1073.

Sharma RA, Van Hazel GA, Morgan B, Berry DP, Blanshard K, Price D, Bower G, Shannon JA, Gibbs P, Steward WP (2007) Radioembolization of liver metastases from colorectal cancer using yttrium-90 microspheres with concomitant systemic oxaliplatin, fluorouracil, andleucovorin chemotherapy. J Clin Oncol 25: 1099-1106.

Smith DB, Neoptolemos JP (2006) Capecitabine in carcinoma of the pancreas. Expert Opin Pharmacother 7: 1633-1639.

Therasse P, Arbuck SG, Eisenhauer EA, Wanders J, Kaplan RS, Rubinstein L, Verweij J, Van Glabbeke M, van Oosterom AT, Christian MC, Gwyther SG (2000) New guidelines to evaluate the response to treatment in solid tumors. J Natl Cancer Inst 92: 205-216.

van Hazel GA, Pavlakis N, Goldstein D, Olver IN, Tapner MJ, Price D, Bower GD, Briggs GM, Rossleigh MA, Taylor DJ, George J (2009) Treatment of fluorouracil-refractory patients with liver metastases from colorectal cancer by using yttrium-90 resin microspheres plus concomitant systemic irinotecan chemotherapy. J Clin Oncol 27: 4089-4095.

van Hazel G, Blackwell A, Anderson J, Price D, Moroz P, Bower G, Cardaci G, Gray B (2004) Randomised phase 2 trial of SIR-Spheres plus fluorouracil/ leucovorin chemotherapy versus fluorouracil/leucovorin chemotherapy alone in advanced colorectal cancer. J Surg Oncol 88: 78-85.

Zheng B, Zheng W, Zhu Y, Lin XY, Xu BH, Chen C (2013) Role of adjuvant chemoradiotherapy in treatment of resectable esophageal carcinoma: a meta-analysis. Chin Med J (Engl) 126: 1178-1182.

This work is published under the standard license to publish agreement. After 12 months the work will become freely available and the license terms will switch to a Creative Commons AttributionNonCommercial-Share Alike 3.0 Unported License. 